taking), synthesising and interpreting this information, and using it to identify needs and problems and the patient's current and potential ability to deal with them. Planning entails setting appropriate goals, considering alternative strategies, and selecting those most likely to achieve the goals. Implementation-putting this plan into action-includes using particular treatments (physical and interactional) and also coordinating a programme of care to ensure the best use of resources and the maximum comfort for the patient. Evaluation means seeing whether the plan has worked and revising the strategies or the goals as necessary.

The thought processes are identical with those used in medicine. Both sorts of practice require sophisticated cognitive and social skills. As the focus of nursing is human response, and as each person is unique, the complexity is infinite and the intellectual demand huge.

Enabling an old lady whose fractured femur has been mechanically repaired to regain mobility, continence, and the self confidence to return to independent living is a considerable intellectual and emotional challenge. So is teaching a couple to manage their baby's tracheostomy at home, or feeding a person whose ability to chew and swallow is compromised by a stroke, especially when the mechanical difficulty is compounded by anger and despair at the degradation of such dependency.

Unfortunately, it is the first perspective-nurses as skilled manual workers-which is the more prevalent and this explains many current ideas about the staffing mix and the deployment of the nursing workforce. Yet it cannot meet patients' expressed needs for coherent and holistic care or extant definitions of quality care.

The problem is that nurses are generally poor at articulating their knowledge and the complexity of their decision making. A recent teaching video shows a district nurse visiting an old woman with an ulcerated leg and applying a dressing. The close up of the nurse's hands is accompanied by a soundtrack of their social conversation. There is no "thought bubble" to show the decision making process-the nurse's clinical observations and assessments go undocumented. Her knowledge is "embedded in practice"'; only the manual task is visible.

Nursing is an ancient art but a young discipline, still developing and refining its conceptual framework. Only now is it beginning to define and classify the phenomena that are its concerns and its interventions and outcomes. Its knowledge base, albeit embedded in clinical practice, has still to be articulated, refined, and tested through scientific research.

Progress during the past 10 years has been dramatic. Research in nursing, especially at doctoral and postdoctoral level, is growing rapidly. For some things, such as managing pain and wounds, supporting the terminally ill, and educating patients, nursing practice can now be based on scientific research and can show clinical effectiveness. Nursing development units, based on the models established in Oxfordshire and Tameside, are growing in number and influence. A professorial clinical nursing unit associated with the new School of Health Care Studies at Middlesex Polytechnic has been established in a small hospital providing care for elderly people in Colindale.

Nursing is already valued - at least by doctors and patients if not always by managers - for its instrumental component (its technical skills) and its expressive component (its emotional, comforting, and nurturing skills). Recognition of nursing's intellectual component is now long overdue.

JUNE CLARK

Professor of Nursing, School of Health Care Studies,

Middlesex Polytechnic Faculty of Social Science,

Enfield, Middlesex EN3 4SF

1 Benner P. From novice to expert: excellence and power in clinical practice. San Francisco: Addison Wesley, 1984

\title{
The other genome
}

\section{Small but significant}

Mitochondria possess their own genetic material, each containing from two to 10 double stranded circular DNA molecules about $16 \cdot 6$ kilobases in length. Large deletions and point mutations of mitochondrial DNA have recently been associated with disease-chiefly mitochondrial myopathies and encephalomyopathies and Leber's hereditary optic neuropathy. More tantalisingly, mutations of mitochondrial DNA may play a part in neurodegenerative disease and normal aging.

Two observations, related to coding function and mode of transmission, pointed to mitochondrial DNA as a potential culprit in the pathogenesis of mitochondrial myopathies and encephalomyopathies. This clinically heterogeneous group of diseases may present with infantile lactic acidosis, progressive external ophthalmoplegia, myopathy with weakness made worse by exercise, and various syndromes predominantly affecting the central nervous system. These include myoclonic epilepsy with ragged red fibres (MERRF) and mitochondrial encephalopathy with lactic acidosis and stroke-like episodes (MELAS). These disorders share the morphological hallmark of structural abnormalities of mitochondria in skeletal muscle, giving rise to the ragged red fibres seen in muscle biopsies stained with the modified Gomori trichrome method or succinate dehydrogenase.

Defects of the mitochondrial respiratory chain and oxidative phosphorylation are found in most patients with these diseases. ${ }^{12}$ The respiratory chain's enzyme complexes contain 13 subunits encoded by mitochondrial DNA. In addition, if patients with mitochondrial myopathies have affected relatives in more than one generation transmission occurs much more often through the maternal line than through the paternal line. Mitochondrial DNA is exclusively maternally transmitted. Another disorder, Leber's hereditary optic neuropathy, which causes subacute blindness mainly in young men, also exhibits maternal inheritance.

The first defect of mitochondrial DNA described in association with human disease was the presence of large deletions in one population of mitochondrial DNA in the muscle of patients with mitochondrial myopathies. ${ }^{3}$ These deletions, which do not seem inheritable, occur in about $40 \%$ of affected adults, all of whom have progressive external ophthalmoplegia and some the Kearns-Sayre syndrome of progressive external ophthalmoplegia, retinopathy, conductive cardiac defects, and ataxia. ${ }^{45}$

Deletions of mitochondrial DNA are also found in lymphocytes of patients with Pearson's syndrome, a disorder comprising neonatal pancreatic and hepatic insufficiency, pancytopenia, and lactic acidosis. ${ }^{6}$ Patients with Pearson's syndrome who survive may develop the features of Kearns- 
Sayre syndrome in later childhood, which suggests that the two disorders represent different phenotypes of the same genetic defect. The mode of initial presentation probably depends on the amount of deleted mitochondrial DNA and its distribution among tissues. ${ }^{7}$ Duplications of mitochondrial DNA have also been described in two patients with progressive external ophthalmoplegia and other features of the KearnsSayre syndrome. ${ }^{8}$

Shortly after the description of deletions of mitochondrial DNA, Wallace and colleagues reported a point mutation of mitochondrial DNA in families with Leber's hereditary optic neuropathy. ${ }^{9}$ This mutation is associated with poor recovery of visual function, and its detection may be useful in confirming the diagnosis, particularly in patients without affected relatives. ${ }^{10}$ Only about two thirds of families with Leber's hereditary optic neuropathy, however, have this mutation; two further point mutations have been reported in this disorder, ${ }^{11} 12$ and other mutations of mitochondrial DNA are likely to account for the disorder in the rest.

The development of blindness in young men at risk is partly related to how much mutant mitochondrial DNA their leucocytes contain, although this is not the whole explanation. Some men with a high proportion of mitochondrial DNA remain unaffected, and a mutation of mitochondrial DNA does not explain the predominance of men affected. These observations may be accounted for by a gene on the $\mathrm{X}$ chromosome that determines susceptibility to visual loss in families with Leber's hereditary optic neuropathy, implying an interaction between the nuclear and mitochondrial genomes in determining the phenotype for this disorder. ${ }^{13}$

Two further point mutations of mitochondrial DNA, both in transfer RNA genes, occur in association with mitochondrial encephalomyopathy syndromes. ${ }^{1+15}$ A mutation at base pair 8344 is the main, but not sole, cause of myoclonic epilepsy with ragged red fibres, and all patients reported on to date have had the core clinical features of myoclonus, ataxia, and various types of seizure. One patient who had died of bulbar palsy was found to have the pathological features of Leigh's syndrome at necropsy; the mutation at base pair 8344 is thus one of several genetic causes of this heterogeneous syndrome. ${ }^{16}$

The phenotype associated with the mutation in mitochondrial encephalopathy with lactic acidosis and stroke-like episodes (at base pair 3423) is much more variable, with only about half the patients presenting with multiple stroke-like episodes. Others may have combinations of myopathy, ataxia, deafness, and progressive external ophthalmoplegia, or myopathy alone. Some patients with either of these two mutations do not have ragged red fibres on muscle biopsy. Each mutation can, however, be detected in leucocyte DNA from nearly all affected patients. ${ }^{16}$ This provides a rapid screening test for mitochondrial disease and could have important implications for diagnosis and genetic counselling in patients with myoclonic epilepsy and strokes at a young age.

Zeviani and colleagues have recently described a maternally inherited genetic defect causing adult onset myopathy and cardiomyopathy, which segregated with a mutation of mitochondrial DNA in the leucine transfer RNA gene. The amount of mutant mitochondrial DNA correlated with metabolic and clinical severity. ${ }^{17} \mathrm{~A}$ further point mutation of mitochondrial DNA, in a gene for subunit 6 of mitochondrial $\mathrm{H}^{+}$ATPase, was described in a family with maternally inherited retinitis pigmentosa, dementia, seizures, ataxia, proximal neurogenic muscle weakness, and sensory neuropathy. ${ }^{18}$ No ragged red fibres were seen on muscle biopsy. It is of interest that the mitochondrial proliferation that gives rise to ragged red fibres occurs only in defects of mitochondrial DNA involving transfer RNAs (deletions or point mutations) and not with mutations involving mitochondrial genes encoding proteins, as in this syndrome and Leber's hereditary optic neuropathy.

Defects of the nuclear genome may also produce abnormalities of mitochondrial DNA. A family has been described with autosomal dominant mitochondrial myopathy in which affected members had multiple deletions of variable length in muscle mitochondrial DNA. A nuclear defect involving the replication of mitochondrial DNA was suggested as its cause. A presumed autosomal recessive disorder giving rise to infantile lactic acidosis was associated with depletion of mitochondrial DNA in affected tissues, including brain, liver, and kidneys. ${ }^{20}$ An acquired form of depletion of mitochondrial DNA in muscle, giving rise to myopathy and ragged red fibres, occurs after long term treatment with zidovudine in patients with AIDS. The drug inhibits mitochondrial $\gamma$ DNA polymerase.

The molecular pathogenesis of diseases related to mitochondrial DNA, particularly their tissue specificity, is unclear. The functional effects of abnormal mitochondrial DNA can be studied by transferring the mutant mitochondrial DNA into human cell lines devoid of mitochondrial DNA. ${ }^{22}$ This experimental model also offers the potential for correcting mitochondrial genetic dysfunction, but the prospects for gene treatment in mitochondrial disease are limited because the most commonly affected tissues - brain and muscle - contain cells that do not divide.

The observation of selective deficiency of complex I in the substantia nigra of patients with Parkinson's disease has drawn attention to the possible role of mitochondrial DNA in the pathogenesis of this disorder. ${ }^{23}$ The lack of excess maternal inheritance in Parkinson's disease makes it unlikely, however, that deficiency of complex I is caused by a primary mitochondrial genetic lesion, although a heteroplasmic mitochondrial DNA defect is the only genetic hypothesis compatible with the finding of similar concordance rates for Parkinson's disease in monozygotic and dizygotic twins.

Abnormalities of mitochondrial DNA, particularly if confined to the substantia nigra, could be secondary to the mutagenic effects of free radicals. Very small amounts of deleted mitochondrial DNA have been described in various regions of the brain in Parkinson's disease, but this is also found in the brains of normal elderly people. ${ }^{2+}$ This is of interest because of suggestions that accumulating mitochondrial DNA mutations may contribute to the aging process; this "holds open the possibility, at least in part, that ageing will be the most widespread mitochondrial disease of all." 25

A E HARDING

Professor of Clinical Neurology, Institute of Neurology,

National Hospital, London WCIN 3BG

1 DiMauro S, Bonilla E, Zeviani M, Nakagawa M, DeVivo DC. Mitochondrial myopathies. An Neurol 1985; 17:521-38.

Pettv RKH, Harding AE, Morgan-Hughes JA. The clinical features of mitochondrial myopathy. Brain 1986;109:915-38.

Holt IJ, Harding AE, Morgan-Hughes JA. Deletions of mitochondrial DNA in patients with mitochondrial myopathies. Nature 1988;331:717-9.

4 Moraes C, DiMauro S, Zeviani M, Lombes A, Shanske S, Miranda AF, et al. Mitochondrial DNA deletions in progressive external ophthalmoplegia and Kearns-Sayre syndrome. $N$ Engl $\mathcal{f}$ Med deletions in prog

5 Holt IJ, Harding AE, Cooper JM, Schapira AHV, Toscano A, Clark JB, et al. Mitochondria myopathies: clinical and biochemical features in 30 cases with major deletions of muscle myopathies: clinical and biochemical features in 30.

6 Rotig A, Cormier V, Blanche S, Bonnefont J-P, Ledeist F, Romero N, et al. Pearson's marrow pancreas syndrome: a multisystem mitochondrial disorder in infancy. $\mathcal{J}$ Clin Invest 1990;86: $1601-8$

7 McShane MA, Hammans SR, Sweeney M, Holt IJ, Beattie TJ, Brett EM, et al. Pearson syndrome and mitochondrial encephalomyopathy in a patient with a deletion of mitochondrial DNA. Am Hum Genet 1990;48:39-42.

8 Poulton J, Deadman ME, Gardiner RM. Duplications of mitochondrial DNA in mitochondrial myopathy. Lancet 1989;i:236-40.

9 Wallace DC, Singh G, Lott MT, Hodge JA, Schurr TG, Lezza AMS, et al. Mitochondrial DNA mutation associated with Leber's hereditary optic neuropathy. Science 1988;242:1427-30.

10 Holt IJ, Miller DH, Harding AE. Genetic heterogeneity and mitochondrial DNA heteroplasmy in Leber's hereditary optic neuropathy. I Med Genet 1989:26:739-43 
11 Howell N, Kubacka M, Xu M, McCullough DA. Leber hereditary optic neuropathy: involvement of the mitochondrial $\mathrm{ND} 1$ gene and evidence for an intragenic suppressor mutation. Am $\mathcal{F ~ H u m}$ (ienet 1991;48:935-42.

12 Huoponen K, Vilkki J, Aula P, Nikoskelainen EK, Savontaus M-L. A new mitochondrial DNA mutation associated with Leber hereditary optic neuroretinopathy. Am f Hum Genet 1991;48: 1147.53 .

13 Vilkki J, Ott J, Savontaus M-L, Aula P, Nikoskelainen EK. Optic atrophy in Leber hereditary optic neuroretinopathy is probably determined by an X-chromosomal gene closely linked to DXS7. Am J Hum (jenet 1991;48:486-91.

14 Shoffner JM, Lott MT, Lezza AMS, Seibel P, Ballinger SW, Wallace DC. Myoclonic epilepsy and ragged-red fiber disease (MERRF) is associated with a mitochondrial DNA tRNA" mutation. Cell 1990;61:931-7.

15 Goto $\mathrm{Y}$, Nonaka I, Horai S. A mutation in the tRNA ${ }^{1+w 1 t k}$ gene associated with the MELAS subgroup of mitochondrial encephalomyopathies. Nature 1990;348:651-3.

16 Hammans SR, Sweeney MGi, Brockington M, Morgan-Hughes JA, Harding AE. Mitochondrial encephalopathies: molecular genetic diagnosis from blood samples. Lancet 1991;337:1311-3.

17 Zeviani $M$, Gellera $C$, Antozzi $C$, Rimoldi $M$, Morandi L, Villani $F$, et al. Maternally inherited myopathy and cardiomyopathy: association with mutation in the mitochondrial DNA TRNA 1.uI'TK. Lancet 1991;338:143-7.
18 Holt IJ, Harding AE, Petty RKH, Morgan-Hughes JA. A new mitochondrial disease associated with mitochondrial DNA heteroplasmy. Am f Hum Genet 1990;46:428-33.

19 Zeviani M, Servidei S, Gellera C, Bertini E, DiMauro S, DiDonato S. An autosomal dominant disorder with multiple deletions of mitochondrial DNA starting at the D-loop region. Natur 1989;339:309-11.

20 Moraes CT, Shanske S, Tritschler H-J, Aprille JR, Andreetta F, Bonilla E, et al. mtDNA depletion with variable tissue expression: a novel genetic abnormality in mitochondrial diseases. Am $\mathcal{J ~ H u m}$ Genet 1991;48:492-501

21 Arnaudo E, Dalakas M, Shanske S, Moraes CT, DiMauro S, Schon EA. Depletion of muscle mitochondrial DNA in AIDS patients with zidovudine-induced myopathy. Lancet 1991;337: $508-10$.

22 King MP, Attardi G. Injection of mitochondria into human cells leads to a rapid replacement of the endogenous mitochondrial DNA. Cell 1988;52:811-9.

Schapira AHV, Cooper JM, Dexter D, Clark JB, Jenner P, Marsden CD. Mitochondrial complex I deficiency in Parkinson's disease. F Neurochem 1990;54:823-7.

24 Ikebe S, Tanaka M, Ohno K, Sato W, Hattori K, Kondo T, et al. Increase of deleted mitochondrial DNA in the striatum in Parkinson's disease and senescence. Biochem Biophys Res Comm $1990 ; 170: 1044-8$.

25 Grossman LI. Mitochondrial DNA in sickness and in health. Am f Hum Gienet 1990;46:415-7.
The use of garlic (Allium sativum) for its purported health giving properties has an honourable tradition, being mentioned in 22 of 800 herbal remedies in the Codex Ebers, an Egyptian medical papyrus of $1550 \mathrm{BC}$. Bottom, however, acknowledged its major side effect when instructing his actors to "eat no onions nor garlic, for we are to utter sweet breath." Garlic has been advocated for various ailments including heart disease, headache, bites, worms, tumours, ${ }^{2}$ cancer, and infections. ${ }^{3}$ Recent work suggests that it has a possible role in reducing vascular disease. Popular interest is currently greatest in Germany, where garlic preparations are the largest selling over the counter drugs. ${ }^{+}$

Garlic's principal active agent is allicin, a sulphur containing compound, which, with its breakdown products, causes the characteristic odour. ${ }^{2}$ Allicin is formed enzymatically from an odourless precursor, alliin, when cloves are mechanically disrupted. Other biologically active compounds related to allicin, such as ajoene, may also be extracted from fresh garlic.

Garlic has beneficial effects on coagulation, platelet aggregation, vasodilatation, and serum lipid concentrations. A fall in fibrinogen ${ }^{56}$ and an increase in fibrinolysis have been reported. ${ }^{5}$ Garlic extract reduces the formation of acute platelet thrombus in vivo in stenosed coronary arteries in $\operatorname{dogs}^{7}$ and synthetic allicin inhibits platelet aggregation in vitro ${ }^{8}$ although the mechanisms are unclear. ${ }^{9-11}$ Garlic's vasodilatory properties have been shown in human skin ${ }^{12}$ and conjunctival vessels. ${ }^{13}$ The packed cell volume, plasma viscosity, ${ }^{6}$ and blood pressure all fall with garlic. ${ }^{5}$ Concentrations of triglycerides and total and low density lipoprotein cholesterol fall with garlic while the concentration of high density lipoprotein cholesterol rises $^{514}$ (although there have been contradictory studies $\left.{ }^{15}\right)$. A recent review concluded that whereas large doses of fresh garlic (7-28 cloves a day) had beneficial effects on cardiovascular risk factors, data for commercial preparations were unconvincing and there was inadequate evidence to recommend garlic supplementation. ${ }^{16}$

One reason for the difficulty in showing the effectiveness of garlic is that active ingredients may be lost in processing. ${ }^{2}$ Carefully dried sliced cloves retain their potency, but extracts or oils prepared by using steam distillation or organic solvents may have little activity. ${ }^{17}$ In addition, the alliin content of natural garlic may vary 10 -fold. Standardising garlic products by using their potential for releasing allicin has been suggested. ${ }^{17}$

Criticisms that previous studies may have used inactive products and were poorly designed ${ }^{16}$ have recently been met by a placebo controlled, randomised, double blind four month study in 261 German patients with hyperlipidaemia. ${ }^{18}$ In those taking $800 \mathrm{mg}$ dried garlic powder a day (Kwai, with $1.3 \%$ allicin) serum concentrations of total cholesterol fell from 6.87 to $6.07 \mathrm{mmol} / \mathrm{l}$ and of triglycerides from 2.55 to $2 \cdot 12 \mathrm{mmol} / \mathrm{l}$. A smell of garlic was reported (most frequently by spouses) in $21 \%$ of treated patients and $9 \%$ of those taking the placebo. A similar dose of garlic taken for three months in another controlled study was associated with a significant fall in blood pressure from $171 / 102$ to $152 / 89 \mathrm{~mm} \mathrm{Hg}$ in hypertensive patients, with one in eight reporting an odour of garlic. ${ }^{19}$

Confusion clouds the issue of "odourless" garlic preparations: Is it the odour of the tablet or recipient that is being described? Some garlic preparations contain no active ingredients and do not smell. Active preparations may themselves be odourless, but if allicin is released on ingestion there will be a substantial chance of a detectable aroma. "Odour blockers" seem ineffective. ${ }^{17}$ Other side effects such as gastrointestinal disturbance, asthma, and contact dermatitis are uncommon, although a spinal haematoma has been attributed to the antiplatelet effects of garlic. ${ }^{20}$

Evidence that garlic reduces cardiovascular risk factors is accumulating but is incomplete. Some garlic preparations may be useful in treating hyperlipidaemia and hypertension, but concomitant reductions in morbidity and mortality remain to be shown. The possibility of detectable aroma seems an inevitable consequence of ingesting an active garlic product. A late twentieth century Bottom would recognise that the potential benefits of garlic may be offset by the social consequences of uttering without sweet breath.

PETER/MANSELL Sentor Registrar JOHN P D RECKLESS Consultant Physician

Royal United Hospital, Bath BA1 3NG

Shakespeare W. A midsummer night's dream. In: Craig WJ. The Oxford Shakespeare. Oxford: Oxfor University Press, 1957:187. (Act IV, scene ii.)

Block E. The chemistry of garlic and onions. Sci Am 1985;252:94-9.

McElnay JC, Li Wan Po A. Dietary supplements (8). Garlic. Pharmaceutical fournal 1991 March 16:324-6.

4 Fulder S. Garlic and the prevention of cardiovascular disease. Cardiology in Practice 1989;7:30-5.

5 Harenberg J, Giese C, Zimmerman R. Effect of dried garlic on blood coagulation, fibrinolysis, platelet aggregation and serum cholesterol levels in patients with hyperlipoproteinaemia. Atherosclerosis 1988;74:247-9.

6 Jung F, Kieswetter H, Mrowietz C, Pindur G, Heiden M, Miyashita C, et al. Akutwirkung eine zusammengesetzten Knoblauchpräparates auf die Fließfähigkeit des Blutes. Zeitschrift für Phytotherapie 1989;10:87-91.

DeBoer LWV, Folts JD. Garlic extract prevents acute platelet thrombus formation in stenosed canine coronary arteries. Am Heart f 1989;117:973-5.

8 Mayeux PR, Agrawal KC, Tou J-SH, King BT, Lippton HL, Hyman AL, et al. The pharmacological effects of allicin, a constituent of garlic oil. Agents Actions 1988;25:182-90. 